\title{
Visión general de los problemas del Gran Santiago
}

Juan Honold Dunner

\section{Filiación}

[1957] Arquitecto de la Dirección de Planeamiento del Ministerio de Obras Públicas de Chile.

\section{Resumen}

Conferencia de J. Honold Dunner, en el Seminario del Gran Santiago realizado en 1957, donde se analizó las relaciones e interdependencias del Gran Santiago con los fenómenos territoriales y regionales.

\section{Palabras claves:}

Región de Santiago. Santiago de Chile. Planificación urbana y regional (1958). Seminario del Gran Santiago - 1958.

\section{Abstract:}

This is the lecture given by J. Honold D. in the Seminario del Gran Santiago 1957 (Seminar on the Greater Santiago). On this Seminar the relation and interdependency of the Greater Santiago and the regional and land phenomena were analyzed.

\section{Key words:}

Region of Santiago. Santiago de Chile. Urban and region planning (1958). Greater Santiago Seminar - 1958".

\section{Sumario}

Introducción

1.-El Gran Santiago y sus proyecciones de alcance nacional y regional

2.- Problemas básicos

Trabajo y producción

Vivienda

Circulación

3.- Síntesis 


\section{Introducción}

Los complejos fenómenos metropolitanos son, naturalmente, difíciles de analizar en forma amplia, en un tiempo tan limitado como el que disponemos; de manera que esta exposición habría que considerarla como una introducción a algunos de los problemas más importantes que hoy día preocupan a especialistas en la materia y al público en general. Sólo se justifica este análisis del Gran Santiago si lo aceptamos como una introducción a las materias que se han programado para las próximas sesiones del Seminario [del Gran Santiago, 1957].

El Planeamiento de cualquier ciudad, además de los estudios del área propiamente urbana, debe ser necesariamente dirigido a la región en que dicha ciudad se encuentra: de ella provienen los materiales utilizados en su estructura física, de ella provienen los abastecimientos para la vida de sus habitantes y ella le proporciona el marco de su paisaje caracterizador.

En el caso de una metrópoli como Santiago, la ciudad ejerce su influencia más allá de la región geográfica y se proyecta en todo el territorio nacional y aún alcanza la escala internacional y continental. Como lógica contrapartida, la metrópoli se relaciona y depende de sus procesos sociales, económicos y culturales, del país entero.

Por ello, el programa del Seminario ha recalcado las relaciones e interdependencias del Gran Santiago con los fenómenos territoriales y regionales.

\section{1.- El Gran Santiago y sus proyecciones de alcance nacional y regional}

El Gran Santiago ha adquirido la escala metropolitana y, como tal, presenta casi todas las características generales positivas o negativas de todas sus semejantes del mundo:

La concentración demográfica, económica, cultural e institucional en el Gran Santiago, es de tal naturaleza, que predomina sin contrapeso sobre todo el país, absorbiendo altos porcentajes de la población y actividades del conjunto.

Este proceso de concentración de nuestra población, economía y cultura, podría ser considerado como un proceso normal, si observamos que el crecimiento metropolitano es un fenómeno mundial generalizado, consecuencia del progreso tecnológico. Sin embargo, la intensidad del crecimiento metropolitano de Santiago, en relación con el del país entero, ha adquirido caracteres que deben ser considerados como patológicos, en especial si se considera el subdesarrollo de ricas regiones de nuestro territorio.

Aun cuando el panorama del centralismo metropolitano es bastante conocido, hemos estimado conveniente señalar algunas de las características del proceso, que no podemos dejar de puntualizar una vez más, por la trascendencia que éste tiene para el país, y porque es la clave para la explicación de muchos fenómenos propios de la 
ciudad, cuyas raíces debemos encontrarlas indudablemente en un deficiente desarrollo del resto del territorio nacional.

A pesar de los esfuerzos que se realizan por intermedio de diversos organismos, tendientes a promover un desarrollo equilibrado de nuestro territorio, no vemos todavía reflejado sus frutos en nuestra realidad del Gran Santiago. Es evidente que los resultados de los programas de desarrollo económico, de otras regiones del país, sólo se reflejarán en las grandes cifras de la demografía y economía metropolitanas, si ellos son mantenidos e intensificados por períodos considerables.

Citaremos las ya conocidas cifras del último Censo de Población y Vivienda del año 1952, que informarán la parte cuantitativa del proceso; pero debemos señalar que hay factores de orden psicológico general, imposibles de ser medidos por cifras, pero que, sin embargo, actúan intensamente. La vida en la metrópoli parece estar incorporada al ideal de nuestros habitantes: radicarse en Santiago, ya sea para desarrollar sus actividades o para aprovechar los beneficios de una jubilación o renta.

Entre los múltiples hechos y factores que acusan el fenómeno de anormal crecimiento metropolitano, podemos destacar:

\section{a) Factores demográficos}

El éxodo de la población rural hacia las ciudades, ha sido extraordinariamente intenso: en el año 1952, el 60\% de la población total del país vivía en zonas urbanas, cifra que indudablemente no puede compararse con los índices de otros países, por cuanto, los criterios para la definición de zonas urbanas pueden variar. Sin embargo, son significativas las cifras correspondientes a países altamente desarrollados. Así:

Gran Bretaña posee un $\quad 80,0 \%$ de población urbana

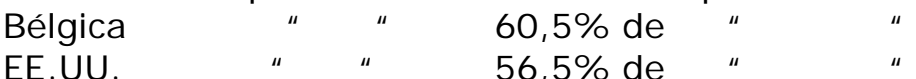

En relación con el total de la población urbana de Chile, que en cifras aproximadas es de 3,6 millones de habitantes, 1,5 corresponde a la población urbana de la provincia de Santiago, es decir:

El $42 \%$ de toda la población rural del país, se ha radicado en la metrópoli.

Conviene recordar el dinamismo de este proceso y señalar que Santiago, en el año 1865 tenía sólo el $6 \%$ de la población total del país; en 1907, alcanzaba al 10\% y al presente, alcanza al $27 \%$ de dicho total de población.

Según estudios realizados en el Ministerio de Obras Públicas, la población de la metrópoli alcanzará los siguientes límites:

En 1960: 2.000 .000 de habitantes

En 1970: 2.800 .000 de habitantes 


\section{En 1980: $\quad 3.000 .000$ de habitantes}

\section{b) Factores económicos}

El proceso de industrialización del país, se ha caracterizado, hasta ahora, porque la mayor parte de las industrias se ha radicado en Santiago.

Entre otras causas han sido determinantes de este emplazamiento, la presencia de una mano de obra calificada y abundante, la existencia de materias primas en casi todos los rubros, la existencia de servicios de energía, agua potable, etc., y tal vez fundamentalmente el mercado consumidor, constituido por la mayor concentración demográfica nacional.

Así podemos comprender cómo el $40 \%$ de la población activa dedicada a la industria, de todo el país, está radicada en la provincia de Santiago y que el $59 \%$ de la producción de toda la industria manufacturera nacional corresponde a la misma zona.

Las actividades comerciales, actividades que son consecuencia y causa a la vez del desarrollo demográfico, aparecen concentradas en el área del Gran Santiago y sus satélites:

El $48 \%$ (aproximando las cifras) de toda la población activa que se dedica al comercio en el país entero se encuentra en esta zona.

\section{c) Factores político-administrativos}

La organización de nuestra Administración Pública, altamente centralizadas es, indudablemente, una de las determinantes de la elevada proporción de la población activa que se dedica a los servicios administrativos en Santiago capitalizando un $42 \%$ del total de la población activa del país.

\section{d) Factores culturales}

Desde los tiempos coloniales, Santiago ha ejercido una hegemonía educacional y cultural y hasta nuestros días es la capital el principal centro de educación en sus distintos grados. Para el mismo año 1952, las universidades existentes en Santiago agrupaban al 75\% de los alumnos universitarios de todo el país.

Y no podemos dejar de señalar que el emplazamiento de la metrópoli, en el centro de gravedad geográfico del país y entre regiones de producción complementaria (minera y agrícola), ha completado el cuadro favorable para un gran desarrollo metropolitano.

Hasta ahora, la evolución social, económica y cultural del país, nos ha llevado a una concentración desequilibrada de nuestra población y economía, cuyas consecuencias negativas se proyectan en todo nuestro territorio, como en la estructura interna de la metrópoli: en efecto, ricas zonas de nuestro territorio, tanto en lo urbano como en lo rural, se encuentran en un proceso de estancamiento o subdesarrollo económico 
incompatible con los objetivos de mejorar los niveles de vida de toda la población, a través de la incorporación de los recursos potenciales de todo nuestro territorio, al proceso económico nacional.

En lo que se refiere al Gran Santiago, el acelerado incremento demográfico ha agravado la ya crítica escasez de viviendas y ha obligado a una costosa ampliación de servicios públicos, tales como abastecimiento de agua potable, sistema de alcantarillado y creado un difícil problema de movilización, cuya solución parece imposible, si no se realizan fuertes inversiones de capital.

Debemos señalar, a manera de ejemplo, que ya se está formando una conciencia entre los diversos organismos del país, reflejada en los planes económicos de la Corporación de Fomento de la Producción y en la labor de la Dirección Nacional de Industrias del Ministerio de Economía, a través de sus reglamentaciones destinadas a la descentralización de industrias de la provincia de Santiago. Otro ejemplo lo tenemos en la formulación del Plan de Desarrollo Agrícola y de Transportes, por el Ministerio de Agricultura, en coordinación con el Ministerio de Obras Públicas y cuya primera aplicación práctica regional la tenemos en el Plan de Desarrollo Agrícola e Higiene Rural de Maule, Ñuble y Concepción.

Estas avanzadas experiencias, nos permiten destacar que la aplicación de esta nueva herramienta que es el Planeamiento Territorial y Regional, es decir, los estudios y soluciones coordinados de los factores sociales, económicos y culturales, con el objetivo de estimular el desarrollo integral del territorio, empieza a formar parte de nuestra organización institucional, abandonando el terreno de las especulaciones más o menos académicas.

Esperamos que, como producto de este Seminario, por la colaboración técnica de los organismos que en él participan, se llegue a perfeccionar las directivas tendientes a encarar en forma efectiva la descentralización metropolitana del Gran Santiago.

\section{2.-Problemas básicos}

Si observamos la actitud de los habitantes que viven en la metrópoli y la situación de los técnicos ante los problemas metropolitanos, podemos señalar:

a) Que, en general, advertimos una cierta indiferencia de la población hacia los problemas básicos de la metrópoli; ella no tiene participación activa en la solución de los problemas; y aún más, puede decirse que los desconoce. Parece ser un fenómeno sociológico comprobado, que cuando las sociedades sobrepasan ciertos límites en su crecimiento, la magnitud y la complejidad de dichos procesos alejan fatalmente al ciudadano común, de los problemas de la comunidad metropolitana. Se valorizan excesivamente aquellos problemas cotidianos, especialmente agudizados en la metrópoli; sin embargo, desconoce e ignora aquellos más importantes que, generalmente, son la causa de los más concretos e inmediatos. 
Muy poco se ha realizado en el sentido de divulgar los problemas económicos, sociales, legislativos y sus consecuencias urbanísticas; señalamos el hecho extraordinario que al presente no exista una buena impresión de un plano de la ciudad de Santiago en que aparezcan sus actuales calles y no contamos con publicaciones regulares en la materia.

b) Por otra parte, debemos destacar también otro hecho singular: los organismos, ya sean universitarios, los servicios estables, municipales o autónomos, realizan una labor de investigación de los problemas urbanos, y encaran su solución en una labor que, en general, debemos calificar de aislada y fragmentaria; lo que redunda frente a la complejidad y magnitud del mecanismo metropolitano en resultados parciales, muchas veces contradictorios en sus concepciones; $y$, en todo caso, faltos de perspectivas y visión del conjunto.

Este Seminario ha tenido como virtud reunir a especialistas de las diversas disciplinas fundamentales. Así, por primera vez, se han reunido para enfocar los problemas básicos de nuestra realidad metropolitana, el médico, el sociólogo, el economista, el abogado, el ingeniero, el arquitecto y otros especialistas.

Los procesos de la metrópoli forman un todo armónico y no es posible actuar en una parte del conjunto sin afectar al total del mismo. Así, los problemas de la salud de la población urbana y rural están estrechamente vinculados a las posibilidades de los servicios técnicos en lo que se refiere al abastecimiento de agua potable, red de alcantarillado; y, fundamentalmente, deberán estar ligados a la edificación de viviendas de interés social; sin embargo, la solución de estos problemas está limitada por la capacidad económica de la ciudad, y del país en general. A ello debemos agregar que toda actuación deberá enmarcarse en las innumerables disposiciones de leyes y reglamentos, ya sea de carácter general u orgánicas de los servicios muchas veces en franco paralelismo y contradicción.

Queremos conocer y ponernos de acuerdo en las líneas fundamentales para enfocar nuestra metrópoli, creemos contribuir a vencer la inercia, más bien, la anarquía que se refleja en nuestra estructura urbana; es por ello que esta primera etapa del Seminario se abocará especialmente al estudio general de la situación: social, económica, legal y administrativamente, en conjunto con aquellos problemas técnicos, clásicos de la planificación urbana.

Señalaremos algunas de las materias que serán abordadas en las próximas sesiones del Seminario:

\section{Aspectos económicos}

El planeamiento de la metrópoli estará condicionado necesariamente por las posibilidades económicas del país, de la propia región en que se encuentra, de la estructura económica de la ciudad. Esperamos que sea posible establecer las bases generales en este Seminario, de un inventario de los recursos materiales, humanos y financieros de la metrópoli, a fin de poder fijar las justas proporciones que en el desarrollo económico general del país corresponda en el futuro a la economía de la 
ciudad. En suma, sería de lato interés poder establecer qué parte de la renta nacional podrá absorber nuestra capital conforme a un problema económico de alcances nacionales.

Diversos organismos realizan planes de desarrollo económico orientados por una política de descentralización económica del Gran Santiago: la labor de la Corporación de Fomento de la Producción, tendiente a desarrollar los diversos rubros de nuestra economía, forma parte de los esfuerzos más decididos en ese sentido; debemos destacar también la labor de la dirección Nacional de Industrias, del Ministerio de Economía, que a través de sus atribuciones específicas estimula la radicación de industrias fuera de los límites de la provincia de Santiago, a la vez que limita las solicitudes para el establecimiento de nuevas industrias en el área metropolitana cuando no existe una justificación económica seria para ello.

Si fijamos nuestra atención en el área propiamente interna de la ciudad, podremos comprobar que la mayoría de los planes de transformación urbana no han podido afrontarse en forma masiva al faltar un plan coordinado de financiamiento, de dichas obras. Debemos tener un conocimiento real y efectivo de la capacidad constructiva, que es indudablemente la mayor del país; pero cuya aplicación se ha dirigido, por la carencia de programas financieros precisos, fundamentalmente hacia la periferia de la ciudad, dispersándose la mayor parte de ellos en una serie de realizaciones aisladas y esporádicas en el área central de la ciudad.

El desfinanciamiento clásico de nuestros municipios ha sido otra de las causas que han imposibilitado una posición más activa de los municipios frente a la realización de obras de urbanismo. No está incorporada a nuestra legislación urbana el mecanismo que permita los municipios financiar parcialmente las obras de progreso urbano, como ser: apertura de calles, plazas y parques, sobre la fase de recuperar parte del mayor valor que dichas obras significan en un determinado sector de la ciudad.

En síntesis, esperamos que en este Seminario se establezcan las líneas generales de una política definida de todos los organismos encargados de velar por el desarrollo económico del país, en orden a establecer las posibilidades y límites del crecimiento metropolitano. Así será posible prever a grandes rasgos en lo que se refiere al planeamiento urbanístico, las áreas destinadas a localizar las actividades económicas de la metrópoli, especialmente en lo que se refiere al destino de la industria y de la agricultura en la región metropolitana.

\section{$\underline{\text { Aspectos sociales }}$}

Las cifras señaladas anteriormente, relativas al crecimiento demográfico de la metrópoli, sólo nos dan una idea numérica del fenómeno humano. Detrás de estas cifras está la realidad social de nuestra población urbana.

El éxodo del campo a la ciudad se manifiesta en Santiago con un promedio de 15.000 personas anuales que se instalan en ella, atraídas por las aparentes mejores condiciones de vida. Esta es una de nuestras realidades sociales metropolitanas: una 
parte considerable de su población es de extracción rural; y en ese permanente proceso de adaptación a las modalidades del trabajo y modo de vida urbana, debemos encontrar muchas de las modalidades del desarrollo social de la comunidad.

Los problemas de la salud de nuestra población metropolitana serán, sin duda laguna, motivo de consideración especial en este Seminario. Una parte considerable de nuestra población urbana vive en condiciones de alta insalubridad ambiental; bástenos citar que en el área metropolitana existían, según censo del año 1952, 75.000 habitantes en poblaciones callampas, y 60.000 en conventillos; y en general se estimó, en aquel año, que un $30 \%$ de nuestra población vivía en condiciones de franca insalubridad, ya sea por la deficiente vivienda, la falta de espacios libres, la proximidad de industrias insalubres, o, lo que es más decisivo, por la falta de servicios de agua potable y la carencia de una adecuada red de alcantarillado.

Tendrá indudablemente que preocuparse este seminario del panorama médicoasistencial en todas sus fases, donde se ha conseguido a través de esfuerzos sostenidos, mejorar los niveles de vida de la población metropolitana, mejoría significativa que acusan los índices estadísticos correspondientes, a pesar de la desfavorable situación ambiental antes descrita.

\section{Problemas legales}

Podemos constatar la falta de realizaciones urbanísticas en las últimas décadas, hecho que ha llamado la atención a especialistas extranjeros y ha sido señalado en diversas ocasiones por el Instituto Nacional de Urbanismo. En efecto, la comuna de Santiago conserva, en general, sus edificaciones de 70 o más años de uso, muchas de ellas en estado ruinoso y en su mayor parte inadecuadas a las funciones que hoy posee la comuna. Podría culparse de esta situación a la falta de disposiciones planificadoras; sin embargo, debemos recordar que la comuna de Santiago, precisamente, tiene un plano oficial de urbanización en vigencia desde el año 1938, proyectado sobre la base de las directivas del arquitecto vienés Karl Brunner, cuyas disposiciones son bastante modestas en lo que se refiere a ensanche de calles, creación de áreas verdes; y en ningún caso, acordes con el acelerado desarrollo metropolitano. El sistema legal que rige, no proporciona las facultades suficientes para que los gobiernos locales estimulen o fuercen el proceso; o lo que es más importante, encaucen las fuerzas económicas particulares en el desarrollo de la ciudad. La ausencia de estos recursos, en lo que respecta a Santiago, ha traído como consecuencia la aprobación de planos reguladores excesivamente limitados en sus concepciones; y lo que es más grave, dejando entregada la transformación de la ciudad casi exclusivamente en manos del vecino que construye su predio, vale decir, entregado al azar del crecimiento vegetativo de la construcción. Al respecto, no parece necesario señalar que la reconstrucción por la vía del interés privado, con las modalidades que se practica, no ha conducido a ningún resultado en las comunas centrales.

El ensanche o prolongación de las calles más necesarias para la circulación proyectada en el plano, desde hace 15 años, no ha progresado prácticamente en nada. Lo mismo 
ocurre con la apertura de las plazas indispensables para desahogar la densidad de la edificación de los barrios.

En síntesis, es necesario dotar a los municipios de las herramientas legales que le permitan materializar sus planes urbanísticos. Debemos señalar, entre otras, la conveniencia de legislar en el sentido de facilitar la mejor utilización del suelo urbano, fraccionado en este momento especialmente en la comuna de Santiago, a fin de crear las condiciones para lograr la remodelación urbana. Deben aprovecharse las experiencias extranjeras para la transformación de sectores urbanos, en sentido de integrar a los vecinos de un mismo sector en sociedades o comunidades legalmente establecidas, de modo que una vez realizada la remodelación, los predios que pasaron transitoriamente a una masa común, se dividan adjudicando nuevos lotes equivalentes a los a los primitivos. En este mismo orden debemos señalar la conveniencia de legislar a favor de los municipios locales, a fin de financiar obras de remodelación urbana, recuperando parte de las inversiones que con ese fin se realicen.

\section{Análisis de las funciones metropolitanas}

Para los efectos del desarrollo de la segunda etapa de este Seminario, se ha dividido el estudio de las diferentes comisiones de acuerdo a los problemas específicos derivados de las principales funciones metropolitanas.

Se ha querido así, darle a este etapa un sentido eminentemente positivo, consecuente con el planteamiento general del torneo que por sobre toda otra consideración es un seminario de los "problemas" del Gran Santiago.

Estos problemas serán analizados desde los diferentes ángulos que la técnica del planeamiento nos proporciona.

Es así como se hará, de cada uno de ellos, un enfoque sociológico; o sea, el aspecto humano y social del problema; un enfoque médico-asistencial que no muestre sus proyecciones en este aspecto y nos presente soluciones prácticas al respecto; un enfoque económico, consistente en una evaluación o levantamiento de cómo se desenvuelve en la actualidad y de sus proyecciones futuras la estructura urbana, así como de las posibilidades financieras de solución; un enfoque legal, político y administrativo que analice la forma en que las leyes de la República, sus Poderes Públicos y sus instituciones públicas tratan de resolver estos problemas, al mismo tiempo que se hagan recomendaciones concretas, $y$, finalmente, para observar el papel que han desempeñado el urbanismo y la ingeniería en el desarrollo urbano, revisar su acción y proyectar en el futuro las posibilidades de solución. Al mismo tiempo, estos diversos planteamientos tendrán en cuenta consideraciones de tipo nacional, regional y urbano.

Los fenómenos que se analizarán desde los puntos de vista anotados, serán:

Trabajo y producción, subdividido en: agricultura, industria, comercio y servicios administrativos. 
Vivienda.

Circulación, en sus diferentes rubros de: Vialidad; tanto terrestre como ferroviaria y aérea; y el transporte en sus rubros de carga y pasajeros.

Equipamiento, tanto administrativo como material. (Servicios de urbanización).

\section{Trabajo y producción}

El primer rubro, "Trabajo y producción", reviste importancia fundamental. Los hombres como seres eminentemente sociales se aglutinaron desde los primeros tiempos por dos razones principales: defenderse de los elementos naturales y de sus enemigos humanos y "trabajar" para producir los elementos y servicios que le permitieran subsistir. Este fenómeno ha seguido siendo válido a través de los tiempos, y es así como podemos observar que donde florecieron fuentes de producción e intercambio, nacieron las ciudades.

Son muy escasas las ciudades del mundo que tienen una razón de ser de otra índole, y si llegamos a describir alguna, en ningún caso ha alcanzado a ser una metrópoli.

Es por las razones expuestas, que el estudio de los factores de trabajo es primordial para el diagnóstico de los problemas urbanos. Creemos que la ordenación y el planeamiento de ellos son una parte importantísima de la ordenación planeamiento del Gran Santiago.

Agricultura. Este rubro vital para el abastecimiento alimenticio de la población, tiene una extraordinaria influencia en los problemas urbanos, aunque por definición se desenvuelve fuera de la ciudad.

Es preciso echar un vistazo al fenómeno nacional: un norte con escasa producción agrícola e inmensas zonas desérticas; luego los valles transversales con sus cultivos ricos, nobles, pero reducidos. Respecto a la primera zona, abastecimiento insuficiente que debe ser reemplazado por productos venidos del sur; respecto a la segunda, autoabastecimiento que consume especialmente Valparaíso y su intercomuna y pequeñas cuotas de estos productos que vienen de Santiago. La tercera zona, valle central, es lógico centro de abastecimiento para la capital, aunque esta se encuentra en el extremo norte del mismo. Cuarta y quinta zonas, sur y austral, dependientes de otros centros consumidores, y exportadoras, por decirlo así, abastecedores de la capital, especialmente productos como: cereales, ganadería, maderas y otros.

La región misma de Santiago se encuentra en proceso de cambio de cultivos extensivos a intensivos, obligada por las exigencias de la metrópoli, que al extenderse, ha hecho crecer a esta zona de influencia. Al mismo tiempo, terrenos agrícolas han sido abandonados en la periferia de la ciudad para ser dedicados a urbanizaciones, sustrayéndolos a la producción. Así, podemos resumir: abastecimientos cada día más 
lejos, desperdicio de buenas tierras. Nadie se ha preocupado de estudiar y definir científicamente las áreas de extensión urbana que menos dañan la economía agraria.

Por otra parte, nuestra agricultura adolece de falta de mecanización y explotación racional, lo que redunda en altos costos, bajos salarios, bajos standard de vida, y como consecuencia de este estado de cosas: constante migración de campesinos hacia la ciudad y en especial hacia la capital, en busca de mejores condiciones.

Es necesario conocer o realizar los estudios de suelos, productividad, demanda de productos, posibilidades de regadío, mecanización, fertilizantes, etc., especialmente en la región de Santiago. Esta será la labor de la comisión en lo que se refiere a este rubro.

Industria. La industria manufacturera es la principal actividad de la población de Santiago; el 33\% de los habitantes activos se dedica a ella; incluyendo los rubros del transporte y la construcción, se llega a la mitad de la población activa. Al mismo tiempo, el $60 \%$ de la producción industrial del país se elabora en Santiago. Esto nos está indicando la importancia de este rubro.

Alrededor de cinco mil industrias, de las más variadas categorías y especies, funcionan en el área metropolitana y ocupan alrededor de doscientas cincuenta mil personas.

La radicación de industrias en la ciudad, no siempre se ha basado en razones valederas, $y$, en muchos casos, no ha sido una consecuencia de los factores económicos.

Han influido muchas veces por razones ajenas a la producción misma: posibilidad de vivir mejor; mejor equipamiento urbano: teatros, colegios, comercio, facilidad para las tramitaciones oficiales, mercado consumidor, etc.

Es necesario estudiar el fenómeno de la radicación industrial, región por región, atendiendo a reales factores de prioridad, y propender a desarrollar otros centros industriales que sirvan para descongestionar Santiago.

La zonificación de las industrias dentro de la ciudad se ha producido, en gran parte, en forma espontánea, generándose zonas industriales mal ubicadas, especialmente con respecto a:

$1^{\circ}$. Vialidad: que no puede resolver el problema de la llegada de materia prima y salida de productos a través del tejido urbano.

$2^{\circ}$ Vivienda: están desvinculadas las zonas industriales y las zonas de vivienda. Hasta ahora las ordenanzas sólo se preocuparon de las primeras, con limitaciones, y las segundas se han hecho al capricho de los urbanizadores de terrenos. Una política racional de construcción de viviendas, de acuerdo a un Plano Regulador que consulte estos aspectos, resolvería, en gran parte, los problemas de transporte de pasajeros en la ciudad. 
$3^{\circ}$ Salubridad: Santiago es una ciudad invadida por los humos y malos olores de la industria nociva, debido a que no se adoptan medidas de protección y a que varias zonas en que están las industrias se encuentran mal ubicadas con respecto a los vientos sur-poniente (vientos dominantes) que acarrean las emanaciones precisamente a las zonas residenciales.

Es urgente estudiar: además de la lógica ubicación de las industrias en el país, una ubicación adecuada en la ciudad, para ellas, con sus redes de vialidad y desvíos ferroviarios, teniendo en cuenta, además, todos los factores que incurren en la radicación y su ubicación con respecto a las viviendas, zonas de protección, etc. Para esto se precisa conocer en detalle el catastro de las industrias existentes, rubros, valor de producción y maquinaria, valor de los edificios, procedencia de las materias privas, mano de obra ocupada, etc.

La mayor parte de las industrias se encuentran ubicadas en edificios inadecuados, y en lugares que han adquirido un exagerado valor comercial. En este momento se está produciendo en forma espontánea, un movimiento de las industrias ubicadas en el centro de la ciudad, hacia la periferia de ellas, que le permite adquirir terrenos a bajo costo, construir edificios espaciosos y adecuados y estar mejor ligados a la vialidad regional por medio de caminos de tránsito rápido y pesado y no por enmarañadas calles, llenas de vehículos que dificultan el movimiento. Es el momento de aprovechar este proceso, en algunos años más será demasiado tarde. Es preciso, por lo tanto, un estudio de la radicación industrial, creación de zonas industriales bien ubicadas con respecto a la vialidad, abastecimiento, energía, vivienda obrera, etc.

Comercio. El fenómeno comercial metropolitano ha tenido un desarrollo paralelo al industrial, que como ya lo dijimos, se ha intensificado en los últimos cincuenta años. A su vez, el desarrollo de la producción, ha traído consigo una concentración demográfica que ha complicado las funciones urbanas, entre ellas, las del intercambio de productos.

El gran comercio, como los mayoristas, la banca, la bolsa, la importación, etc., no es otra cosa que la réplica financiera de los fenómenos de producción. Su desarrollo en la ciudad ha tendido a concentrarse en lo que se llama propiamente el centro, por cuanto, su interdependencia mutua así lo ha exigido. Posteriormente, con el crecimiento urbano, se ha producido cierta vitalización de algunos otros sectores de la ciudad, y es así cómo algunas de estas instituciones han abierto sucursales en los núcleos vecinales de mayor importancia.

Además, el centro de la urbe tiene otro tipo de negocios, que sirven a toda la ciudad por su magnitud e importancia, como tiendas, restaurantes, y toda clase de variados negocios se alinean en espera del cliente que acude al centro desde los barrios de la ciudad.

El comercio menor, cuya distribución aparece repartida en los diferentes sectores urbanos, forma pequeños sub-centros que le dan a cada barrio la posibilidad de 
autoabastecerse. Inclusive en el centro, existen negocios de esta índole para los habitantes del sector.

De la exposición se desprende que el ordenamiento de este factor presenta una menor dificultad que el de la agricultura e industria.

Por la propia necesidad lógica de vender, el comercio se ha agrupado en torno a los centros vecinales que le dan vida.

Santiago, que es una ciudad de muy escasa caracterización vecinal, debe propender a vitalizar estas agrupaciones a través de sus Ordenanzas y Planos Reguladores. Debe tender a otorgar una mayor autosuficiencia a sus barrios, tratando de lograr completar su equipo local. Debe tender a descentralizar la función comercial, en lo que se refiere a artículos de consumo habitual y periódico. Debe darle a su centro comercial, la real categoría de una "city", incrementando ese sentido de concentración que espontáneamente manifiesta.

Para controlar este fenómeno, se precisa de estudios, que nos den a conocer, la ubicación de las zonas comerciales, con detalles de los rubros, e importancia de los negocios, los capitales empleados y el personal que ocupan. Estudiar la ciudad en conjunto y detectar las verdaderas unidades de habitación y sus necesidades, para lograr hacer de ellas unidades vecinales o barrios autosuficientes, en cuanto a sus servicios vecinales. Esta detección se hace por un proceso de superposición de las diferentes características del tejido urbano: vialidad, industria, comercio, administración, equipamiento, densidad de población, actividades, etc.

El fenómeno administrativo también tiene atingencia en esto. Es fundamental para la creación de barrios y jerarquización de los núcleos urbanos.

En la actualidad, el país, como ya se ha dicho, sufre de una organización centralizada que contribuye a agravar los problemas expuestos. Es preciso contar con una organización administrativa nacional que contemple la creación de otros centros administrativos además de la capital. Nuestra conformación administrativa actual ha obligado a una distribución super centralizada. Para tramitar cualquier papel, los habitantes de las provincias deben venir a Santiago y, a su vez, los habitantes de los barrios deben acudir al centro. Es preciso dotar, por lo tanto, además, a los barrios de su equipo administrativo; se requiere distribuir orgánicamente, Correos, Registros Civiles, Retenes de Carabineros, Juzgados, Oficinas de Impuestos, etc., que subrayen el sentido autárquico que deben tener los barrios.

Respecto a la administración central, no cabe duda que su ubicación sólo puede ser, junto al poder central, y en ese sentido la zona cívica de la ciudad puede seguir completándose hasta contener todos los servicios que correspondan.

Como en el caso anterior, para ordenar este factor es preciso conocer la organización administrativa, su interdependencia, la ubicación y destino de las zonas y edificios administrativos, el personal ocupado, etc. 


\section{Vivienda}

Generalidades. Se ha indicado las proyecciones del crecimiento demográfico metropolitano, y es precisamente el factor más decisivo del gravísimo déficit de viviendas del Gran Santiago (el incremento ha sido de $42 \%$, si comparamos los censos de 1940 y 1952).

A la densidad de población del Gran Santiago debemos considerarla relativamente baja, si se toma en cuenta el total de la superficie urbana. Sin embargo, la densidad en algunos sectores de la comuna de Santiago y zonas adyacentes supera los cuatrocientos habitantes por hectárea, llegando en sectores a 600 y 800 habitantes por ha. Debemos hacer presente que estas densidades son extraordinariamente elevadas, si consideramos la baja densidad de edificación de los sectores mencionados, donde predominan habitaciones de uno o dos pisos, siendo causa del extraordinario hacinamiento de la vivienda en donde es habitual que familias numerosas vivan en una o dos piezas.

Tendencias de la edificación en el área metropolitana. Si observamos la extensión del área edificada podemos destacar:

A. Los dos tercios del crecimiento urbano actual han sido producto de la edificación en el presente siglo.

En el sector oriente y sur de Santiago, se han formado áreas residenciales que cuentan en general con adecuados servicios de urbanización y sus edificaciones de un nivel superior y de lujo en muchos sectores. Han sido formados en parte considerable por la labor de las Cajas de Previsión y por la iniciativa privada, estimulada esta última por la Ley Pereira.

B. Por el contrario, los sectores norte y poniente han tenido un auge extraordinario con una edificación de calidad media y en su mayor parte deficiente, existiendo especialmente en los suburbios serios problemas derivados de la carencia de servicios de urbanización

C. Otra parte del esfuerzo constructivo se ha vaciado a un reducido sector del centro comercial y administrativo de la ciudad, donde podemos constatar un cambio en la fisonomía urbana.

Sin embargo, tenemos que reconocer, desde le punto de vista urbanístico, que muchas de las nuevas edificaciones no cumplen en general con disposiciones racionales de aireación, asoleamiento, motivadas por una ordenanza que permite una densidad de edificación incalificable, especialmente dado el fraccionamiento de la propiedad. Tras las nuevas fachadas se esconden los ya habituales patios y pozos de luz de reducidas dimensiones inaceptables para una edificación en altura como la que establece dicha 
ordenanza y a los cuales parece nos hemos acostumbrado en nombre del "progreso urbano".

Déficit habitacional metropolitano. No corresponde a una exposición general del problema de Santiago detallar las condiciones de insalubridad del ambiente de esas poblaciones, resumidas en falta o deficiencia de los servicios de urbanización, hacinamiento, falta de espacios libres, e insalubridad proveniente de emanaciones industriales o contaminaciones de canales, etc.

Hablar del déficit habitacional del Gran Santiago parece ser una consideración académica, si consideramos las abultadas cifras de los habitantes que moran en poblaciones callampas y conventillos: 75.000 en poblaciones callampas y 60.000 para los últimos, si comparamos con la capacidad constructiva general del país.

Evolución de la edificación en el Gran Santiago. Labor de las instituciones de Previsión. Hemos señalado anteriormente los factores que hasta ahora han actuado como freno para la reedificación del casco o área envejecida de la ciudad, por la carencia de herramientas que permitan una remodelación de dichas áreas conforme a normas urbanísticas más efectivas.

La edificación de viviendas por los organismos de previsión es una herramienta de enorme valor para la remodelación urbana (varias Sociedades EMPART han construido en la "zona carcomida"); sin embargo, no ha sido posible concentrar su esfuerzo en determinados sectores hasta el presente.

La Corporación de la Vivienda, a pesar de poseer facultades legales para expropiar terrenos, para sus poblaciones, no ha podido utilizarla en el sector antiguo de la ciudad, ya que la densidad de población existente es relativamente elevada y tendría, por consiguiente, que desalojar habitantes, en mayor proporción, que aquellos que puedan ubicarse en la nueva población; sumado a los trámites legales que implican una expropiación a 30 ó 40 propietarios por ha, que es la subdivisión predial normal. Sus posibilidades se han dirigido preferentemente a los suburbios en las proximidades de los centros de trabajo industrial.

Creemos que en el desarrollo de este Seminario podrán establecerse planteamientos generales que permitan una utilización más racional del suelo urbano, suburbano y rural del área metropolitana, a fin de:

- Estimular el uso intensivo del suelo agrícola circundante.

- Encauzar la edificación de viviendas conforme a un planteamiento técnico definido a desarrollar en el tiempo, cuyos puntos básicos deberían considerar condiciones, entre otras:

a) Promover el saneamiento o erradicación de las viviendas más insalubres, como ser, poblaciones, "callampas" y conventillos.

b) Remodelación de las áreas estacionarias del "casco antiguo de la ciudad". 
c) Desarrollar los actuales pueblos satélites (como Puente Alto, San Bernardo, Maipú, Quilicura), a fin de absorber el futuro crecimiento demográfico y descongestionar las áreas centrales.

\section{Circulación}

Generalidades. Es en este aspecto de la metrópoli donde podemos apreciar la falta de una adaptación a las nuevas necesidades planteadas por los transportes mecanizados contemporáneos. En efecto, el primitivo trazado colonial se adaptaba a la modalidad del transporte en base de vehículos de tracción animal de reducida velocidad (10 $\mathrm{km} /$ hora), y hoy día conservamos con ligeros ensanches el mismo trazado.

Se han creado nuevas avenidas en los sectores recientemente urbanizados de la periferia, llamadas a continuarse en las comunas centrales donde es precisamente mayor la congestión.

Diversos proyectos de realizar aperturas de nuevas avenidas, tendientes a la descongestión vial han fracasado, por las mismas razones que han hecho imposible la remodelación de las áreas del casco central del Gran Santiago.

Circulaciones principales. Podemos esquematizar tres movimientos tres movimientos fundamentales de relaciones de tránsito:

La ciudad con la región y el país.

El centro comercial y administrativo con el resto de la ciudad.

Las comunas periféricas entre sí.

Puntualizando:

1. Sabemos que por la disposición radial de las carreteras regionales, ellas vacían su caudal de circulación hacia el sector central obligadamente, dado que no existe ningún sistema distribuidor hasta el momento.

2. El movimiento desde y hacia el centro de la ciudad es más intenso que el anterior, como lo demuestra el análisis del tránsito de una vía como la Gran Avenida, que es del orden de los 18.000 vehículos diarios a la altura del Ferrocarril de Circunvalación y de sólo 3.000 vehículos, a la altura del río Maipo, vale decir, donde el tránsito es típicamente regional.

3. El movimiento de las comunas entre sí responde generalmente a las relaciones entre vivienda y trabajo de carácter industrial, es decir, el mayor porcentaje de nuestra población activa.

Podemos concluir, corroborando así las mediciones realizadas por los organismos municipales y estatales, que se produce la mayor concentración de tránsito en el área central de la ciudad, donde se dan las condiciones mas negativas en cuanto a vías adecuadas, y donde es difícil habilitar nuevas. 
Agreguemos, además, la circunstancia de que, especialmente en algunos sectores, no existen calles que por sus mayores anchos pudieran servir de base para una diferenciación de la circulación, con la cual poder evitar la actual situación en que prácticamente todas las calles del sector central tienen la misma jerarquía, lo que obliga por consiguiente a reducir la velocidad de circulación por los cruces demasiado próximos impuestos por la manzana colonial.

No existe hasta la fecha [1958] un sistema de circulación jerarquizado de acuerdo con el destino funcional:

Vías de alta velocidad.

Calles y avenidas de velocidad mediana (distribuidoras).

Calles vecinales destinadas al uso local con velocidades mínimas.

Bases posibles para encarar una solución. En síntesis, debe procurarse un sistema general, que supere los límites comunales, que sirva a las necesidades del tránsito regional e intercomunal antes señaladas, además de un sistema distribuidor de orden comunal y vecinal.

El Ministerio de Obras Públicas [de Chile], a través de sus Direcciones de Planeamiento y Vialidad, ha planificado un sistema periférico de vías que organizan y empalman la vialidad regional con la circulación propiamente urbana. Se han reservado los terrenos necesarios para ello en varios sectores se espera poder completar en breve plazo dicha labor.

Debemos insistir, sin embargo, que la creación de un sistema integral de vías en la metrópoli sólo podrá ser completado sobre la base de herramientas financieras y legales adecuadas para estos fines.

Es evidente que la locomoción colectiva metropolitana ha visto agravadas sus clásicas deficiencias por dos fenómenos:

a) Longitud de los recorridos a causa de la extensión de la superficie urbana.

b) Congestión de las áreas centrales, donde resulta difícil poner mayor número de vehículos en servicio, por la saturación existente, del tránsito en las actuales condiciones.

Ferrocarril metropolitano. El déficit existente actualmente en la capacidad de los servicios de transporte colectivo, estimado en 700.000 setecientos mil pasajes diarios, es síntoma de la actual congestión de dicho servicio. No corresponde en este momento señalar las causas de dicha situación, pero sí, analizar una solución alternativa de mucha actualidad, como es el Ferrocarril Metropolitano.

El primer estudio serio sobre la construcción del ferrocarril subterráneo para Santiago data del año 1925, y hoy día, ya existen proyectos y especificaciones para su construcción. 
Entre las ventajas de la solución del ferrocarril subterráneo podemos señalar, entre otras: permite desarrollar una mayor velocidad, descongestiona la superficie y puede ser realizado evitando costosas demoliciones para el ensanche inmediato de las vías de superficie. El avance de las técnicas de los ferrocarriles subterráneos posibilita realizar combinaciones con sistemas de superficie, como monorrieles elevados, y, en general, con los sistemas de trenes rápidos que sirven a los suburbios y satélites metropolitanos.

La justificación económica de este proyecto no corresponde a esta visión general de los problemas, procederá abordarla en la etapa siguiente del Seminario, conjuntamente con las nuevas soluciones técnicas señaladas anteriormente.

\section{3.-Síntesis}

La complejidad y magnitud de los fenómenos metropolitanos y esta rápida visión de algunos de los problemas más importantes, no deben impedirnos para resumir ciertas ideas centrales, que, estamos seguros, serán precisadas y ampliadas durante este Seminario:

-El proceso metropolitano del Gran Santiago es factor decisivo y principal en el desarrollo social y económico del país. Por lo tanto, la solución de sus problemas debe ser encarada a través de una política del planeamiento territorial y regional de nuestra realidad social, económica, cultural e institucional.

- La solución del problema urbano no sólo deberá basarse en medidas y planes a realizar en el interior del área urbana, sino que también y fundamentalmente en la organización y planeamiento de la región, única medida que hará posible una efectiva descongestión de la ciudad hipertrofiada, mediante el desarrollo de un sistema regional de satélites y áreas de renovación económica.

-En lo que se refiere a la solución de los problemas urbanísticos, deberá tomarse en cuenta que el área metropolitana es una unidad urbana, y que como tal, posee problemas comunes que deben ser resueltos en conjunto, salvando los límites comunales existentes en la actualidad. Existen diversas fórmulas para encarar el gobierno metropolitano; sin embargo, para el caso de nuestra organización institucional, parece fundamental insistir en la conveniencia de mantener y desarrollar la autonomía municipal establecida en nuestra Carta Fundamental y en la Ley de Municipalidades, y, a la vez, deberá procurarse una fórmula que permita coordinar los complicados procesos metropolitanos en su conjunto.

- La realización de las obras de urbanismo y servicios públicos que el Gran Santiago necesita requieren la adopción de una serie de medidas específicas para el área metropolitana, de orden financiero, legal y administrativo. Existe urgencia en legislar en ese sentido, por cuanto cualquier nuevo plan técnico urbanístico estará condenado al fracaso si no se proveen las herramientas básicas antes mencionadas. 
http://revistaurbanismo.uchile.cl

Fuente: UNIVERSIDAD DE CHILE, Departamento de Extensión Cultural, Boletín Informativo №34, 2a y 3ạ Etapas del Seminario del Gran Santiago, Santiago de Chile, octubre de 1958.

Nota: Juan Honnold Dunner es Arquitecto U. Chile, 1952. Profesor en la U. Chile y sede de Valparaíso entre 1956-80, y en el Centro Chileno de Productividad de la Construcción 1993-95. Jefe del Plan Intercomunal Santiago, en la Dirección de Planeamiento del M.O.P. 1954-60. Jefe del D. de Urbanismo y Vivienda de la Dirección de Arquitectura del M.O.P. J efe del D. de Areas Metropolitanas de la Dirección de Desarrollo Urbano del MINVU, 1965-67. Director de Planificación del Desarrollo Urbano del MINVU, 1973-77. Asesor del MINVU, 1978. Funda la oficina de Consultores en Planificación Urbana y Regional Honold-Correa y Asociados, en 1982. Asesor del Consejo Regional Metropolitano desde 1996. 